\title{
Postoperative Results of Off-Pump Coronary By-pass Grafting in Elderly Patients: A Single Center Experience
}

\author{
M. Biçer*, B. Özdemir, R. İşçimen, D. Saba, M. Yanar, O. Tüydeş, I. Şenkaya and M. Cengiz \\ Uludað University Medical Faculty, Department of Cardiovascular Surgery, Görükle, 16059 Bursa Turkey
}

\begin{abstract}
Aim: We aimed to report our postoperative results in elderly patients that had off-pump coronary bypass grafting.
Method: Data of 173 patients with isolated coronary bypass 70 years of age or older were retrospectively evaluated. One month follow-up data were evaluated in all patients. After getting verbal informed consent a total of 91 patients were included in the quality of life assessment via EuroQoL form. The data of patients with age of 70-74 and 75 or older were compared.
\end{abstract}

Results: The mean ages of patients at age of $70-74$ and $\geq 75$ were $71.69 \pm 0.16$ and $76.81 \pm 0.23$ years; respectively. Eleven cases had in-hospital mortality (\%6 of 173 patients). The mean follow-up period for the group that were reached for EuroQoL assessment was 46,3 $\pm 20,8$ months. The percent of cases among the whole study group that had participated in the quality of life questionnaire were in good condition in terms of mobility, self-care, usual activities, pain/discomfort, anxiety/depression were $\% 75, \% 87, \% 81, \% 92$ and \%89; respectively.

Discussion: Off-pump coronary bypass operation may be safely used in elderly patients with high quality of life and low morbidity and mortality.

Key Words: Older age, Coronary bypass, Beating heart, Quality of life, EuroQoL.

\section{BACKGROUND}

A number of non-randomized studies have shown that off-pump coronary by-pass grafting (CABG) is as safe as onpump surgery, and in experienced hands offers less early complications, particularly in those patients with significant co-morbidity. In high-risk groups, particularly in groups over 70 years of age, there is a reduction in the incidence of cerebral injury when an off-pump technique is employed [1]. However, randomized trials have not yet revealed a significant reduction in morbidity or mortality [1]. Zhang et al. in their very recent study suggested that off-pump CABG was a safe alternative to on-pump CABG in dialysis patients. By avoiding cardiopulmonary bypass, they had less perioperative blood utilization, myocardial infarction(MI), and hospital mortality [2]. In this study we aimed to report our results of one month follow-up of patients that had off-pump CABG at an age of 70 years or older. Also in cases that we were able to reach we evaluated the quality of life by using the EoroQoL score.

\section{MATERIAL AND METHODS}

The study was conducted at the Cardiovascular Surgery Department of Applied Research Center for Health of Uludağ University Medical Faculty in Bursa Turkey. The data of patients who were 70 years or older and had isolated CABG between October $1^{\text {st }}$ of 2000 and January $31^{\text {st }}$ of

*Address correspondence to this author at the Uludad University Medical Faculty, Department of Cardiovascular Surgery, Görükle, 16059 Bursa Turkey; Tel: 0090224 2952300; Fax: 0090224 4428698;

E-mail: mbicer23@yahoo.com
2008 were collected. A total of 173 patients were included for evaluation of results of the one month follow-up and mortality data. There was in-hospital mortality in eleven patients. Among the remaining 162 patients in 33 cases we were not able to reach the patients of his/her relatives. Nine of the 129 cases had mortality in the late postoperative period that was evident by the hospital records and information gathered by the relatives of the patients. The diagnoses in these cases were; intracranial hemorrhage in one, mesentery embolism in one, gastrointestinal tract perforation in one, chronic renal failure in one, leukemia in one, heart failure in one and undetermined in three patients. We excluded 10 patients that had history of stroke prior to surgery $(n=2)$, and cases with NYHA functional class IV $(\mathrm{n}=8)$. Among the remaining 110 patients 91 gave their verbal consent to participate in the questionnaire regarding the quality of life. To those patients we applied EuroQoL questionnaire by phone. Via EuroQoL we evaluated the mobility, self-care, usual activities, pain/discomfort and anxiety/depression of those 91 cases. We also asked the presence of angina pectoris and history of myocardial infarction. We accepted the mortality that had occurred in 30 days after the operation as in-hospital mortality. In case of MI we accepted a creatinin kinase myocardial band (CK-MB) serum level $>50 \mathrm{U} / \mathrm{I}$ and a presence of new $\mathrm{Q}$ wave in ECG as diagnostic criteria.

The EuroQoL questionnaire (Table 1) is composed of a five-item health status measure that includes mobility, selfcare, usual activities, pain, discomfort, and anxiety and/or depression. Answers received a score ranging from 1 to 3 (depending on whether patients perceived no problems as 1 , some problems as 2 , or significant problems as 3 ) in that aspect of their health [3]. 
Table 1. EuroQoL Score Form

\begin{tabular}{|c|c|c|}
\hline Mobility & \multicolumn{2}{|c|}{ Option } \\
\hline I have no problems in walking about & $\bar{\square}$ & 1 \\
\hline I have some problems in walking about & $\square$ & 2 \\
\hline I am confined to bed, unable to walk without help & $\square$ & 3 \\
\hline \multicolumn{3}{|l|}{ Self-Care } \\
\hline I have no problems with self-care & $\square$ & 1 \\
\hline I have some problems washing or dressing myself & $\square$ & 2 \\
\hline I am unable to wash or dress myself & $\square$ & 3 \\
\hline \multicolumn{3}{|l|}{ Usual Activities } \\
\hline I have no problems performing my usual activities & $\square$ & 1 \\
\hline I have some problems with performing my usual activities & $\square$ & 2 \\
\hline I am unable to perform my usual activities & $\square$ & 3 \\
\hline \multicolumn{3}{|l|}{ Pain / Discomfort } \\
\hline I have no pain or discomfort & $\square$ & 1 \\
\hline I have moderate pain or discomfort & $\square$ & 2 \\
\hline I have extreme pain and discomfort & $\square$ & 3 \\
\hline \multicolumn{3}{|l|}{ Anxiety / Depression } \\
\hline I am not anxious or depressed & $\square$ & 1 \\
\hline I am moderately anxious or depressed & $\square$ & 2 \\
\hline I am extremely anxious or depressed & $\square$ & 3 \\
\hline
\end{tabular}

\section{OFF-PUMP CORONARY BYPASS OPERATION}

Off-pump CABG was performed with the Medtronic Octopus II or III stabilizing device (Medtronic, Minneapolis, Minn) for coronary stabilization and deep pericardial traction sutures for cardiac displacement. Technical details of surgery for patients are described in the literature [4].

\section{STATISTICAL ANALYSIS}

Pearson Ki-Square Test and Mann-Whitney U test were the tests used in the statistical analyses with JMP 6.0 (SAS Institute, Cary, NC, USA) Software System. Statistical significance was assumed in case of a $p$ value $<0.05$. The results are expressed as mean \pm standard deviation.

\section{RESULTS}

We divided the whole group into two according to their ages as patients having age of lower than 75 and patients 75 years of age or older. The mean ages of patients at age of $70-74$ and $\geq 75$ were $71.69 \pm 0.16$ and $76.81 \pm 0.23$ years; respectively. The preoperative demographical characteristics are given in Table 2. The mean follow-up period for the group that were reached for EuroQol assessment was 46, $3 \pm 20,8$ months. The number of female that were included in the EuroQoL assessment at age of 70-74 and $\geq 75$ were 18 (\%27) and 9 (\%34); respectively. The postoperative data are given in Table 3. The data regarding the questionnaire for quality of life is given in Table 4. Eleven cases had in-hospital mortality (\%6 of 173 patients). One of these eleven patients died after discharge and the remaining died in hospital. The distribution of the cases and the in-hospital mortality rates per year are given in Table $\mathbf{5}$. There was angina in six and MI in five patients among the whole study group $(n=173)$. The percent of cases among the whole study group that had participated in the quality of life questionnaire were in good condition in terms of mobility, self-care, usual activities, pain/discomfort, anxiety/depression was $\% 75, \% 87, \% 81, \% 92$ and $\% 89$; respectively. The mobility domain scores in patients at age of 70-74 and $\geq 75$ were $1.30 \pm 0.49$ and $1.15 \pm 0.36$ respectively $(\mathrm{p}=0.36)$. Self care was $1.15 \pm 0.40$ in patients at age of 70-74 years and $1.11 \pm 0.32$ in patients $\geq 75$ years of age $(p=0.32)$. Usual activities also was not significantly different between the patients at age of 70-74 and $\geq 75$ years of age $[1.07 \pm 0.44$ and $1.15 \pm 0.36$ respectively $(p=0.21)]$. Pain/Discomfort domain was $1.07 \pm 0.26$ in patients at age of $70-74$ and $1.07 \pm 0.27$ in patients $\geq 75$ years of age; $(\mathrm{p}=0.5)$. Anxiety/Depression scores in patients at age of 70-74 and $\geq 75$ years were $1.12 \pm 0.41$ and $1.23 \pm 0.58$; respectively $(\mathrm{p}=0.8)$.

\section{DISCUSSION}

Patients aged 70 years or older undergoing coronary artery bypass grafting with the use of a heart-lung machine (on-pump) are at a higher risk of mortality and morbidity than younger patients [5]. However elderly patients have an acceptable operative risk and the long-term functional results are satisfying [6,7]. Traditionalists have raised concerns about off-pump CABG's effectiveness, durability, and func- 
Table 2. Preoperative Demographical Characteristics

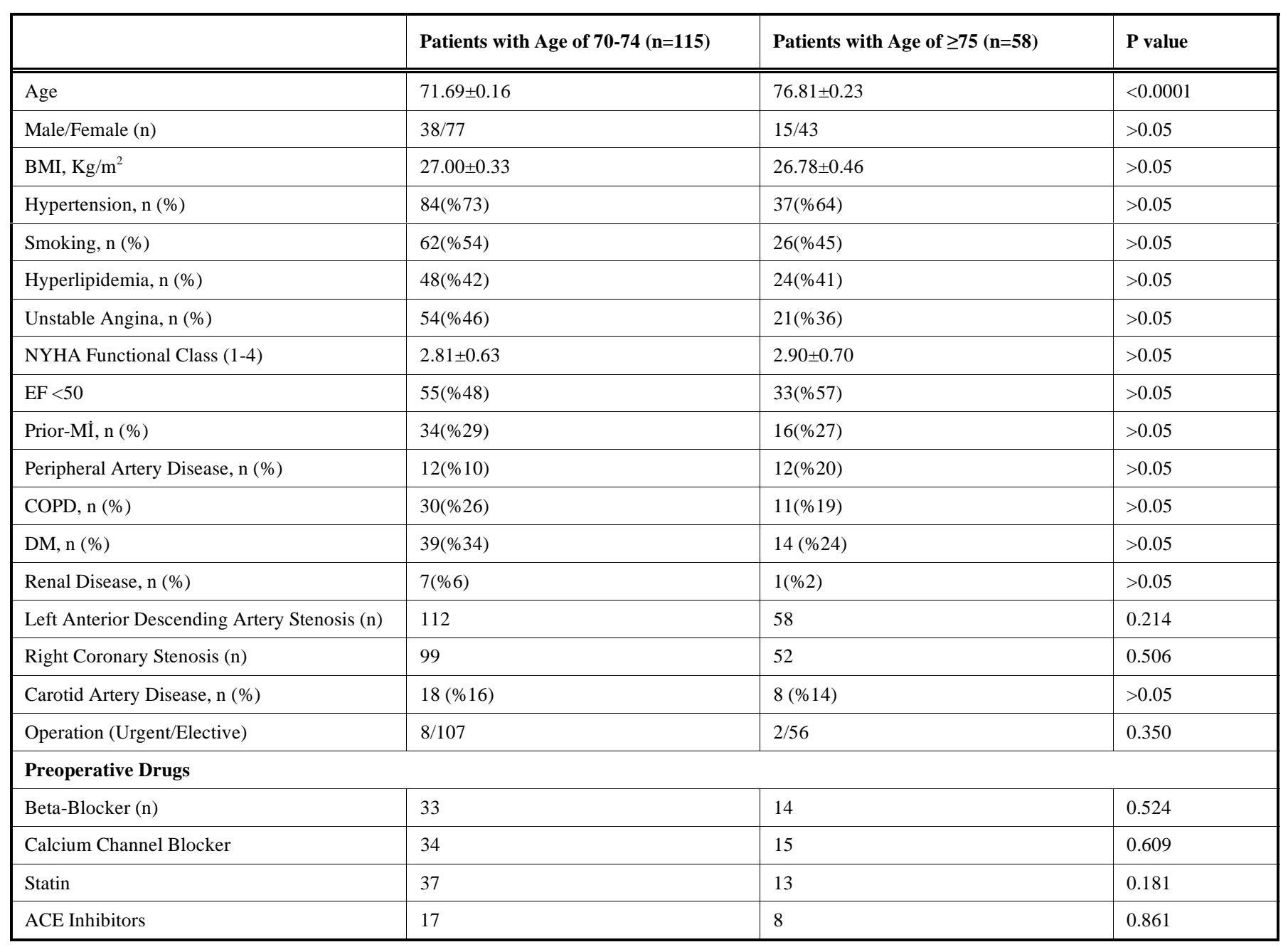

BMI; body mass index, NYHA; New York Heart Association.

EF; ejection fraction, MI; myocardial infarction.

TIA; transient ischemic attack.

COPD; chronic obstructive pulmonary disease, DM; diabetes mellitus.

tional recovery compared with the conventional on-pump revascularization approach [8]. In a study Kapetanakis et al. demonstrated that both conventional and off-pump coronary artery bypass surgery groups had an overall improvement in function and quality of life at six months. His prospective study revealed that there was no statistically significant difference in the patient's expected postoperative quality of life with either surgical approach [9].

In our study the off-pump CABG patients had an inhospital mortality of $\% 6$ which we think is comparable to the results of other reports. The patients that were 75 years or older had significantly higher mortality compared to the patients at age of 70-74 years in our study (Table 3). In a study by Baskett et al. the death rates in patients who underwent elective CABG at age of 70-74 and 75-79 were 3,8\% and $6,6 \%$; respectively [10]. In a study, Li et al. reported an observed mortality of $3.22 \%$ for the bypass graft surgery (CABG) with cardiopulmonary bypass (CCB) cohort and $2.62 \%$ for off-pump CABG $(\mathrm{p}<0.05)$ [11]. In his study the mean age of the patients operated with off-pump CABG was $67 \pm 11$ years. Octogenarians were found to have more renal insufficiency as patient characteristics compared to nonoctogenarians undergoing CABG [10]. In our study postoperative renal failure was more frequent in patients older than 75 years of age. Duration in the intensive care unit was longer in the group 75 years of age or older in our study compared to patients at age of 70-74 years old $(2.48 \pm 0.23$ versus $2.01 \pm 0.16)(\mathrm{p}=0.03)$. In a recent study Markou et al. investigated quality of life by EuroQol domains in 568 patients that had primary isolated CABG majority of being operated on-pump (95.8\%) [12]. In his study on the basis of their age, study group had been classified in three groups. He did not find significant difference in intensive care unit stay between the groups with age of less than 65 years, 65 to 74 , and with 75 years of age or older.

Also in his study, for the different domains of the EuroQoL registration, there was a significant improvement for the five domains in group with less than 65 years of age. In group with an age of 65 to 74 years, there was only a significant improvement for the domains daily activities and pain. In group with patients with 75 years of age or older only daily activities improvement reached statistical significance. 
Table 3. Postoperative Data

\begin{tabular}{|c|c|c|c|}
\hline & Patients with Age of 70-74 $(n=115)$ & Patients with Age of $\geq 75(n=58)$ & P Value \\
\hline Number of Distal Anastamoses & $2,8 \pm 0,75$ & $2,5 \pm 0,72$ & $\mathbf{0 , 0 2}$ \\
\hline \multicolumn{4}{|l|}{ Postoperative Laboratory } \\
\hline $\mathrm{Hb}(\mathrm{g} / \mathrm{dL})$ & $10.27 \pm 0.14$ & $10.32 \pm 0.19$ & 0.836 \\
\hline Thrombocyte & $207.84 \pm 7.80$ & $195.18 \pm 10.56$ & 0.336 \\
\hline Creatinin Kinase & $685.75 \pm 92.48$ & $700.01 \pm 127.6$ & 0.928 \\
\hline CK-MB & $34.23 \pm 2.85$ & $32.72 \pm 3.97$ & 0.758 \\
\hline Triglyceride & $96.42 \pm 64.32$ & $59.55 \pm 28.36$ & 0.296 \\
\hline Post-operative MI (n) & 5 & 0 & 0.861 \\
\hline Mesenteric Ischemia & 1 & 1 & NS \\
\hline Postoperative Neurological Complications & 7 & 8 & 0.0891 \\
\hline Mechanical Respiratory Support Duration (h) & $8.13 \pm 0.67$ & $9.57 \pm 0.94$ & 0.215 \\
\hline Days in the ICU & $2.01 \pm 0.16$ & $2.48 \pm 0.23$ & $\mathbf{0 . 0 3 3}$ \\
\hline Days in Hospital & $8.48 \pm 0.41$ & $9.31 \pm 0.58$ & 0.252 \\
\hline Mortality (n, \%) & $4(2.31 \%)$ & $7(4.05 \%)$ & 0.028 \\
\hline
\end{tabular}

Table 4. EuroQoL Score Values of the Patients

\begin{tabular}{|c|c|c|c|}
\hline Mobility Score & $1.30 \pm 0.49$ & $1.15 \pm 0.36$ & 0,36 \\
\hline $2(n)$ & $18(28 \%)$ & $4(15 \%)$ & \\
\hline $3(n)$ & $1(1 \%)$ & 0 & \\
\hline $2(n)$ & $8(13 \%)$ & $3(12 \%)$ & \\
\hline $3(n)$ & $1(\% 1)$ & 0 & \\
\hline Usual Activities Score & $1.07 \pm 0.44$ & $1.15 \pm 0.36$ & 0,21 \\
\hline $1(n)$ & $52(80 \%)$ & $22(85 \%)$ & \\
\hline $1(\mathrm{n})$ & $60(92 \%)$ & $24(92 \%)$ & \\
\hline $2(n)$ & $5(8 \%)$ & $2(8 \%)$ & \\
\hline $3(n)$ & 0 & 0 & \\
\hline Anxiety / Depression Score & $1.12 \pm 0.41$ & $1.23 \pm 0.58$ & $\mathbf{0 , 8}$ \\
\hline $1(\mathrm{n})$ & $59(91 \%)$ & $22(85 \%)$ & \\
\hline $2(n)$ & $4(6 \%)$ & $2(7,5 \%)$ & \\
\hline $3(n)$ & $2(3 \%)$ & $2(7,5 \%)$ & \\
\hline
\end{tabular}


Table 5. The Distribution of the Cases and Mortality Rates Per Year

\begin{tabular}{|c|c|c|}
\hline Years & Number of Patients & Mortality \% Per Year \\
\hline \hline 2000 & 8 & 0 \\
\hline 2001 & 1 & 0 \\
\hline 2002 & 18 & 11,1 \\
\hline 2003 & 41 & 14,3 \\
\hline 2004 & 29 & 0 \\
\hline 2005 & 31 & 3,2 \\
\hline 2006 & 23 & 4,3 \\
\hline 2007 & 3 & 0 \\
\hline 2008 & 19 & 5,3 \\
\hline
\end{tabular}

This seems to be consistent with Jarvinen who concluded that patients aged more than 75 are likely to derive less benefit from CABG in terms of certain aspects of quality of life [13]. Elderly patients undergoing revascularization have better health status at 4 years than do those in the same age group who do not undergo revascularization. These findings reported by Michelle et al. suggest that age should not deter against revascularization given the combined survival and quality-of-life benefits [14]. Both on-pump and off-pump patients improved in health-related quality of life scores after CABG surgery in a study conducted by Jensen et al. [15]. No clinically relevant difference between the groups could be demonstrated.

The evaluation of quality of life revealed that majority of elderly patients were in good condition after of-pump CABG (Table 4). The results of research of Merkouris et al. indicated that 12 months after surgery a high percentage of patients presented significant improvements in quality of life $(80.4 \%)$. However, the findings of this study illustrated that despite great overall improvement, patients still experience severe emotional problems 12 months postoperatively including questions about self-esteem, selfconfidence, and dependence on others [16]. Some researchers found that $15-37 \%$ of patients, regardless of age, present exacerbation of post-surgery quality of life after CABG surgery [17, 18]. However, older patients present many problems in the immediate postoperative period. According to Khatri and her colleagues, the elderly only experienced greater worry and depression in the immediate postoperative period (6 weeks post surgery) [19]. The Quality of life assessment in our study included the late term results. In long term, the improvement in angina and functional capacity probably would have caused a satisfactory result in perception of mood state.

The weakness of the study is the lack of a control group. Also, the quality of life assessment would be more valuable if it had been a prospective study. In this case we would also be able to show the improvement or deterioration in quality of life in case of having preoperative data. However we be- lieve the mortality and morbidity data of the elderly patients with off-pump CABG will have value for our colleagues.

In conclusion, off-pump CABG has satisfactory results in patients with 70 years of age or older. Also perception of quality of life evaluated by EuroQoL questionnaire showed that majority of patients were in good condition in late postoperative period.

\section{CONFLICT OF INTERESTS}

None

\section{REFERENCES}

[1] Pepper J. Controversies in off-pump coronary artery surgery. Clin Med Res 2005; 3:27-33.

[2] Zhang L, Boyce SW, Hill PC, et al. Off-pump coronary artery bypass grafting improves in-hospital mortality in patients with dialysis-dependent renal failure. Cardiovasc Revasc Med 2009; 10: $12-6$.

[3] Russell LB, Gold MR, Siegel JE, Daniels N, Weinstein MC. Recommendations of the panel on cost-effectiveness in health and medicine. JAMA 1996; 276: 1253-8.

[4] Puskas JD, Williams WH, Duke PG, et al. Off pump coronary artery bypass grafting provides complete revascularization with reduced myocardial injury, transfusion requirements, and length of stay: a prospective randomized comparison of two hundred unselected patients undergoing off-pump versus conventional coronary artery bypass grafting. J Thorac Cardiovasc Surg 2003; 125:797808.

[5] Bainbridge D, Martin J, Cheng D. Off pump coronary artery bypass graft surgery versus conventional coronary artery bypass graft surgery: a systematic review of the literature. Semin Cardiothorac Vasc Anesth 2005; 9:105-11.

[6] Tsai T, Chaux A, Matloff JM, et al. Ten-year experience of cardiac surgery in patients aged 80 years and over. Ann Thorac Surg 1994; 58: 445-51.

[7] DuCailar C, Chaitman BR, Castonguay Y. Risks and benefits of aortocoronary bypass surgery in patients aged 65 years or more. Can Med Assoc J 1980; 122: 771-9.

[8] Lytle BW. Minimally invasive cardiac surgery. J Thorac Cardiovasc Surg 1996; 111: 554-5.

[9] Kapetanakis EI, Stamou SC, Petro KR, et al. Comparison of the quality of life after conventional versus off-pump coronary artery bypass surgery. J Card Surg 2008; 23: 120-5.

[10] Baskett R, Buth K, Ghali W, et al. Outcomes in octogenarians undergoing coronary artery bypass grafting. CMAJ 2005; 172: 1183-6.

[11] Li Z, Yeo KK, Parker JP, Mahendra G, Young JN, Amsterdam EA. Off-pump coronary artery bypass graft surgery in California, 2003 to 2005. Am Heart J 2008; 156: 1095-102.

[12] Markou AL, van der Windt A, van Swieten HA, Noyez L. Changes in quality of life, physical activity, and symptomatic status one year after myocardial revascularization for stable angina. Eur $\mathrm{J}$ Cardiothorac Surg 2008; 34: 1009-15.

[13] Järvinen $\mathrm{O}$, Saarinen $\mathrm{T}$, Julkunen J, Huhtala H, Tarkka MR. Changes in health-related quality of life and functional capacity following coronary artery bypass graft surgery. Eur J Cardiothorac Surg 2003; 24: 750-56.

[14] Michelle M. Graham1 MM, Norris CM, Galbraith PD, Knudtson ML, Ghali WA for the APPROACH Investigators. Quality of life after coronary revascularization in the elderly. Eur Heart J 2006; 27: 1690-8.

[15] Jensen BØ, Hughes P, Rasmussen LS, Pedersen PU, Steinbrüchel DA. Health-related quality of life following off-pump versus onpump coronary artery bypass grafting in elderly moderate to highrisk patients: a randomized trial. Eur J Cardiothorac Surg 2006; 30: 294-9.

[16] Merkouris A, Apostolakis E, Pistolas D, Papagiannaki V, Diakomopoulou E, Patiraki E. Quality of life after coronary artery bypass graft surgery in the elderly. Eur J Cardiovasc Nurs 2009; 8:74-81. 
[17] Chocron S, Etievent JP,Viel JF, et al. Prospective study of quality of life before and after open heart operations. Ann Thorac Surg 1996; 61: 153-7.

[18] Rumsfeld JS, MaWhinney S, McCarthy M Jr, et al. Health-related quality of life as a predictor of mortality following coronary artery bypass graft surgery. Participants of the Department of Veterans
Affairs Cooperative Study Group on processes, structures, and outcomes of care in cardiac surgery. JAMA 1999; 281: 1298-303.

[19] Khatri P, Babyak M, Clancy C, et al. Perception of cognitive function in older adults following coronary artery bypass surgery. Health Psychol 1999; 18: 301-6.

Received: February 23, 2009

Revised: February 28, 2009

Accepted: Mach 3, 2009

(c) Biçer et al.; Licensee Bentham Open.

This is an open access article licensed under the terms of the Creative Commons Attribution Non-Commercial License (http://creativecommons.org/licenses/by$\mathrm{nc} / 3.0 /$ ) which permits unrestricted, non-commercial use, distribution and reproduction in any medium, provided the work is properly cited. 